\title{
Correction to: Confidence intervals for robust estimates of measurement uncertainty
}

\author{
Peter D. Rostron ${ }^{1}$ (D ) Tom Fearn ${ }^{2} \cdot$ Michael H. Ramsey $^{1}$
}

Published online: 25 February 2021

(c) The Author(s) 2021

\section{Correction to: \\ Accreditation and Quality Assurance (2020) 25:107-119 https://doi.org/10.1007/s00769-019-01417-4}

The notations $F_{p, \nu 1, \nu 2}$ and $\chi_{p, \nu}^{2}$ in Eqs. (1), (2) and (3) correspond to that of Graybill [8], for whom the probability $p$ is that in the upper tail. Thus they correspond to the inverse cumulative distribution functions of the respective distributions evaluated for a probability of $1-p$ and not for a probability $p$ as stated in the paragraph immediately above these equations. The correct interpretation was used in coding the RANOVA3 software and in all the other computations reported in the paper. is:

The originally published text at the top of the third page

$F_{p, \nu 1, \nu 2}$ is the inverse cumulative distribution function (cdf) of the F probability distribution with degrees of freedom $\nu 1, \nu 2$ for a probability $p$, and $\chi_{p, \nu}^{2}$ is the inverse cdf of the chi-squared distribution with degrees of freedom $v$ for probability $p$.

The corrected text therefore is:

$F_{p, \nu 1, \nu 2}$ is the inverse cumulative distribution function (cdf) of the F probability distribution with degrees of freedom $\nu 1, \nu 2$ for a probability $1-p$, and $\chi_{p, \nu}^{2}$ is the inverse cdf of the chi-squared distribution with degrees of freedom $v$ for probability $1-p$.

The original article can be found online at https://doi.org/10.1007/ s00769-019-01417-4.

Peter D. Rostron

pr52@outlook.com

Michael H. Ramsey

m.h.ramsey@sussex.ac.uk

1 School of Life Sciences, University of Sussex, Falmer, Brighton BN1 9QG, UK

2 Department of Statistical Science, University College London, Gower Street, London WC1E 6BT, UK
Open Access This article is licensed under a Creative Commons Attribution 4.0 International License, which permits use, sharing, adaptation, distribution and reproduction in any medium or format, as long as you give appropriate credit to the original author(s) and the source, provide a link to the Creative Commons licence, and indicate if changes were made. The images or other third party material in this article are included in the article's Creative Commons licence, unless indicated otherwise in a credit line to the material. If material is not included in the article's Creative Commons licence and your intended use is not permitted by statutory regulation or exceeds the permitted use, you will need to obtain permission directly from the copyright holder. To view a copy of this licence, visit http://creativecommons.org/licenses/by/4.0/.

Publisher's Note Springer Nature remains neutral with regard to jurisdictional claims in published maps and institutional affiliations. 